\title{
Liquid Chromatography-Tandem Mass Spectrometry for the Simultaneous Determination of Doxorubicin and its Metabolites Doxorubicinol, Doxorubicinone, Doxorubicinolone, and 7-Deoxydoxorubicinone in Mouse Plasma
}

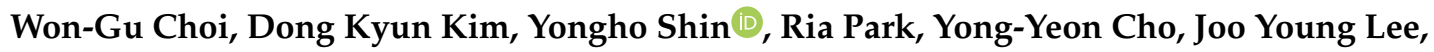 \\ Han Chang Kang ${ }^{(D)}$ and Hye Suk Lee *(i)
}

BK21 PLUS Team for Creative Leader Program for Pharmacomics-based Future Pharmacy, College of Pharmacy, The Catholic University of Korea, Bucheon 14662, Korea; cwg0222@catholic.ac.kr (W.-G.C.); kdk3124@catholic.ac.kr (D.K.K.); driger6103@catholic.ac.kr (Y.S.); hyacinthy7@catholic.ac.kr (R.P.); yongyeon@catholic.ac.kr (Y.-Y.C.); joolee@catholic.ac.kr (J.Y.L.); hckang@catholic.ac.kr (H.C.K.)

* Correspondence: sianalee@catholic.ac.kr; Tel.: +82-2-2164-4061

Academic Editors: In-Soo Yoon and Hyun-Jong Cho

Received: 21 February 2020; Accepted: 8 March 2020; Published: 10 March 2020

\begin{abstract}
Doxorubicin, an anthracycline antitumor antibiotic, acts as a cancer treatment by interfering with the function of DNA. Herein, liquid chromatography-tandem mass spectrometry was for the first time developed and validated for the simultaneous determination of doxorubicin and its major metabolites doxorubicinol, doxorubicinone, doxorubicinolone, and 7-deoxydoxorubicinone in mouse plasma. The liquid-liquid extraction of a $10 \mu \mathrm{L}$ mouse plasma sample with chloroform:methanol (4:1, $v / v)$ and use of the selected reaction monitoring mode led to less matrix effect and better sensitivity. The lower limits of quantification levels were $0.5 \mathrm{ng} / \mathrm{mL}$ for doxorubicin, $0.1 \mathrm{ng} / \mathrm{mL}$ for doxorubicinol, and $0.01 \mathrm{ng} / \mathrm{mL}$ for doxorubicinone, doxorubicinolone, and 7-deoxydoxorubicinone. The standard curves were linear over the range of $0.5-200 \mathrm{ng} / \mathrm{mL}$ for doxorubicin; $0.1-200 \mathrm{ng} / \mathrm{mL}$ for doxorubicinol; and $0.01-50 \mathrm{ng} / \mathrm{mL}$ for doxorubicinone, doxorubicinolone, and 7-deoxydoxorubicinone in mouse plasma. The intra and inter-day relative standard deviation and relative errors for doxorubicin and its four metabolites at four quality control concentrations were $0.9-13.6 \%$ and $-13.0 \%$ to $14.9 \%$, respectively. This method was successfully applied to the pharmacokinetic study of doxorubicin and its metabolites after intravenous administration of doxorubicin at a dose of $1.3 \mathrm{mg} / \mathrm{kg}$ to female $\mathrm{BALB} / \mathrm{c}$ nude mice.
\end{abstract}

Keywords: doxorubicin; doxorubicinol; doxorubicinolone; doxorubicinone; 7-deoxydoxorubicinone; LC-MS/MS; mouse plasma

\section{Introduction}

Doxorubicin (Adriamycin) is an anthracycline glycoside antitumor antibiotic used as a first-line drug in combination with other chemotherapy drugs for various types of cancers, including breast cancer, bladder cancer, soft tissue and bone sarcomas, malignant lymphoma, and acute lymphocytic leukemia [1]. However, it also has serious adverse effects: dose-dependent cardiotoxicity and myelosuppression [2,3]. Several nanotechnology-based doxorubicin preparations have been developed since the 1990s [3-5]. Some of these are commercially available, such as PEGylated liposomal Doxil ${ }^{\circledR}$ and liposomal Myocet ${ }^{\circledR}$, and others (e.g., micellar NK-911 ${ }^{\circledR}$, nanoparticles of Livatag ${ }^{\circledR}$, and polymer-drug conjugates PK1 and PK2) are currently undergoing clinical trials [3,4]. 
Doxorubicin is metabolized to doxorubicinol, doxorubicinone, doxorubicinolone, 7deoxydoxorubicinone, 7-deoxydoxorubicinolone, 4-O-demethyl-7-deoxydoxorubicinolone, 4-demethyl7-deoxydoxorubicinolone sulfate, and 4-demethyl-7-deoxydoxorubicinolone glucuronide by carbonyl reduction, deglycosylation, $O$-demethylation, O-sulfation, and O-glucuronidation (Figure 1) [6-10]. Doxorubicinol, a major alcohol metabolite of doxorubicin formed by carbonyl reductases 1 and 3 , is implicated in off-target cardiotoxicity of doxorubicin-treated patients [3,7-10].

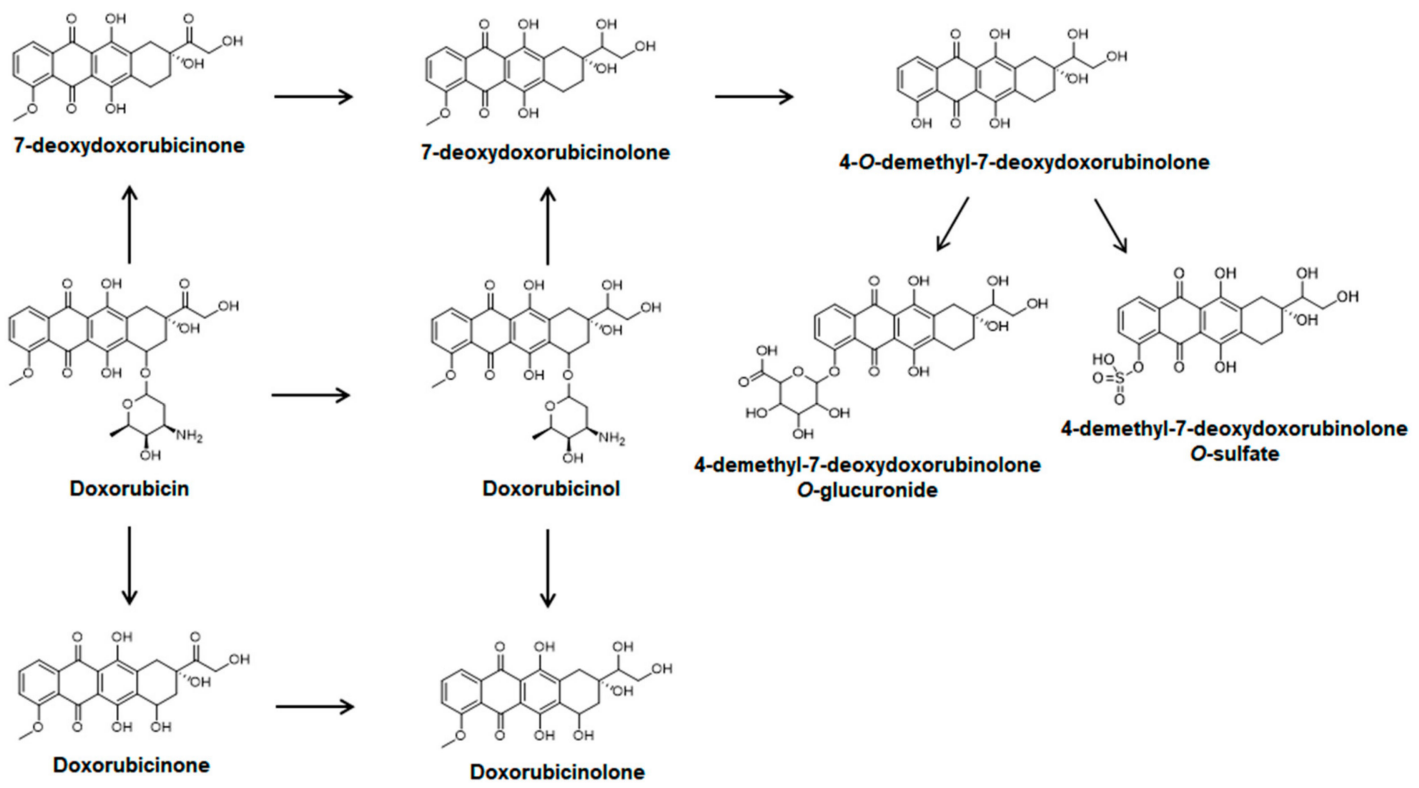

Figure 1. Metabolic pathways of doxorubicin.

High-performance liquid chromatography (HPLC) with fluorescence [11-19] or ultraviolet (UV) [20,21] detection, LC with mass spectrometry (LC-MS) [22,23] or tandem mass spectrometry (LC-MS/MS) [24-36], and capillary electrophoresis [37-39] methods have been used to analyze doxorubicin alone or with its metabolite doxorubicinol in various biological matrices, such as blood, serum, plasma, cells, and tissues. Protein precipitation with methanol, acetonitrile, or acetone [13-15,18,19,21,22,25-27,31,32,34,35]; liquid-liquid extraction with ethyl acetate or a mixture of chloroform and methanol [11,16,17,20,29,33]; and solid-phase extraction [23,24,28,30,36] methods have been used as sample clean-up procedures for a variety of biological samples. These methods resulted in lower limit of quantification (LLOQ) levels of $0.2-50 \mathrm{ng} / \mathrm{mL}$ for doxorubicin [11-36]; 0.5-1.25 ng/mL for doxorubicinol $[11,23,25,27,28,30,33]$; and $1-5 \mathrm{ng} / \mathrm{mL}$ for doxorubicinone, doxorubicinolone, 7-deoxydoxorubicinone, and 7-deoxydoxorubicinolone [11,12] using large volumes of blood, plasma, or serum (50-1000 $\mu \mathrm{L})$. To date, no studies have used an LC-MS/MS method for the simultaneous determination of doxorubicin and its major four metabolites in plasma samples, but some have used HPLC with fluorescence detection [11,12].

We have developed, for the first time, a sensitive and rapid LC-MS/MS method for the simultaneous determination of doxorubicin and its major four metabolites, i.e., doxorubicinol, doxorubicinone, doxorubicinolone, and 7-deoxydoxorubicinone, using the least mouse plasma volume $(10 \mu \mathrm{L})$ to evaluate the pharmacokinetics of doxorubicin and metabolites in formulation development and drug-drug interaction studies of doxorubicin. We successfully applied the method to characterize the pharmacokinetics of doxorubicin and its four metabolites after intravenous injection of doxorubicin at $1.3 \mathrm{mg} / \mathrm{kg}$ dose to female BALB/c nude mice. 


\section{Results}

\subsection{LC-MS/MS Analysis}

To optimize the sensitive and simultaneous determination of doxorubicin and its four metabolites (i.e., doxorubicinol, doxorubicinone, doxorubicinolone, and 7-deoxydoxorubicinone) in a single run, various columns, such as Halo C18 (2.7 $\mu \mathrm{m} ; 2.1 \mathrm{~mm}$ i.d. $\times 50 \mathrm{~mm}$; Advanced Materials Technology, Wilmington, DE, USA), Acquity UPLC BEH C18 (1.7 $\mu \mathrm{m} ; 2.1 \mathrm{~mm}$ i.d. $\times 50$ mm; Milford, MA, USA), and Luna Omega $\mathrm{C}_{18}(1.6 \mu \mathrm{m} ; 2.1 \mathrm{~mm}$ i.d. $\times 50 \mathrm{~mm}$; Phenomenex, Torrance, CA, USA) were assessed using gradient elution of methanol or acetonitrile and water with $0.1 \%$ formic acid as the mobile phase. The Luna Omega C18 column exhibited better separation, an excellent peak shape, and good sensitivity for the analytes using a gradient elution of $0.1 \%$ formic acid in $95 \%$ methanol and $0.1 \%$ formic acid in $0.1 \%$ formic acid in 5\% methanol compared with the Halo C18 and Acquity BEH C18 columns. Using methanol instead of acetonitrile [19-33] as the strong eluent of the mobile phase resulted in increased ionization efficiency and linearity range for the five analytes. Daunorubicin, an analog of doxorubicin, was selected as and the internal standard (IS).

The MS/MS parameters for all of the analytes were optimized using the flow-injection method to achieve maximum sensitivity, and selective reaction monitoring (SRM) transitions of the precursor ion $\left([\mathrm{M}+\mathrm{H}]^{+}\right.$or $\left.[\mathrm{M}+\mathrm{Na}]^{+}\right)$to the intense product ion were used for data acquisition due to the high selectivity and sensitivity (Figure 2). The positive ion mode yielded better sensitivity than the negative ion mode for all of the analytes.
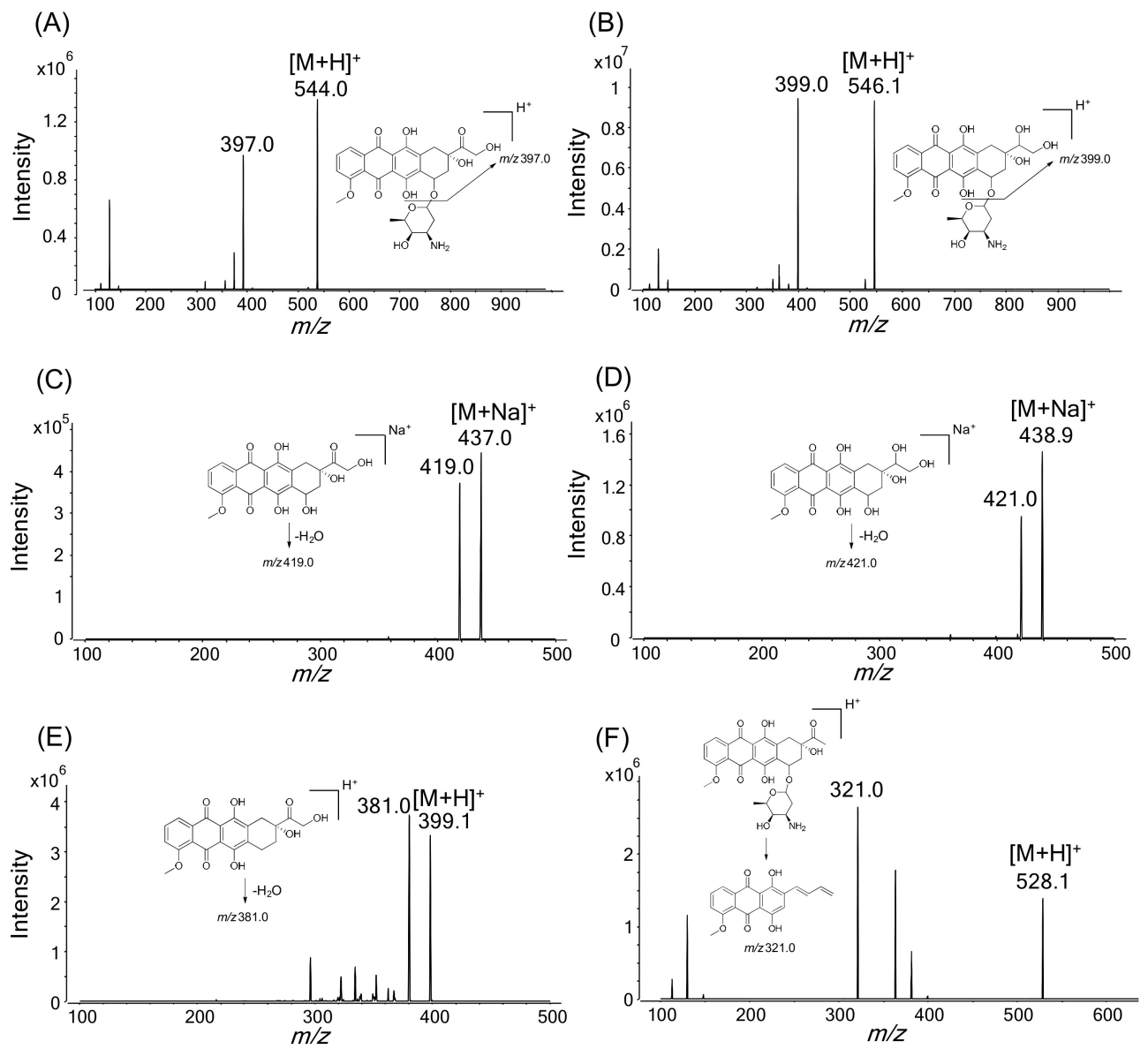

Figure 2. Product ion spectra of (A) doxorubicin, (B) doxorubicinol, (C) doxorubicinone, (D) doxorubicinolone, (E) 7-deoxydoxorubicinone, and (F) daunorubicin (internal standard). 
No significant interference peaks were observed in the retention times of any of the analytes, indicating good method selectivity (Figure 3A). Figure 3B presents typical SRM chromatograms of the five analytes and IS in mouse plasma sample spiked with five analytes at LLOQ levels. The retention times were as follows: doxorubicin, $2.0 \mathrm{~min}$; doxorubicinol, $1.9 \mathrm{~min}$; doxorubicinone, $2.5 \mathrm{~min}$; doxorubicinolone, $2.3 \mathrm{~min}$; 7-deoxydoxorubicinone, $2.8 \mathrm{~min}$; daunorubicin (IS), $2.2 \mathrm{~min}$. Figure 3C presents representative SRM chromatograms of a plasma sample obtained $15 \mathrm{~min}$ after intravenous administration of doxorubicin in a mouse.

(A)
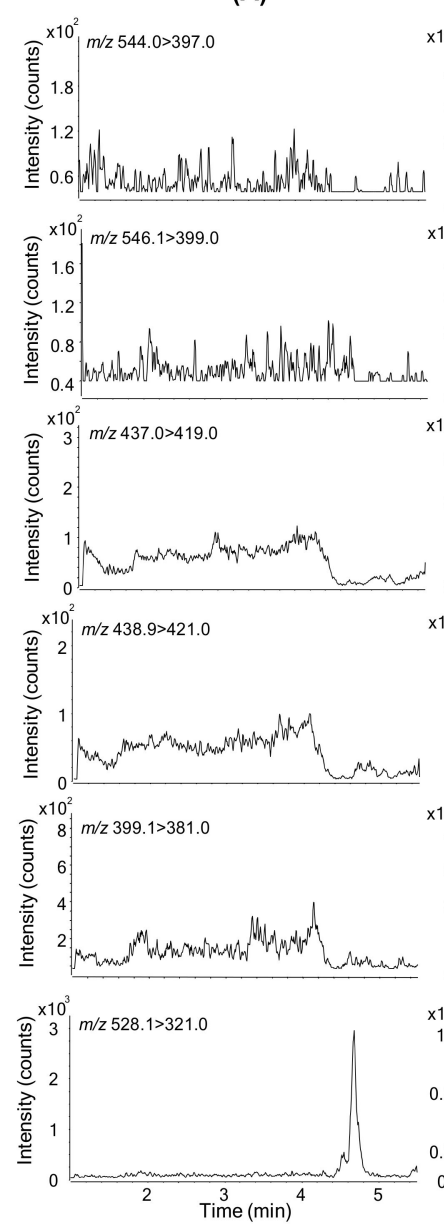

(B)
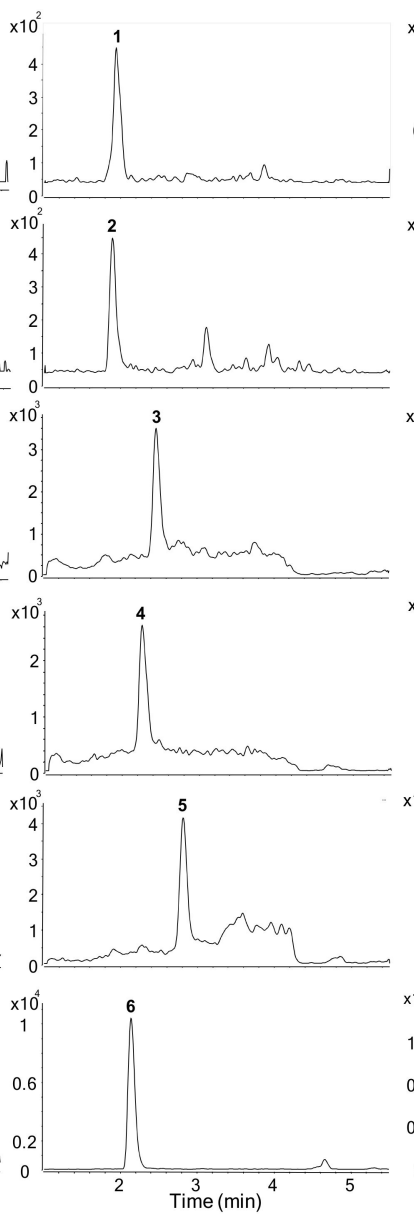

(C)
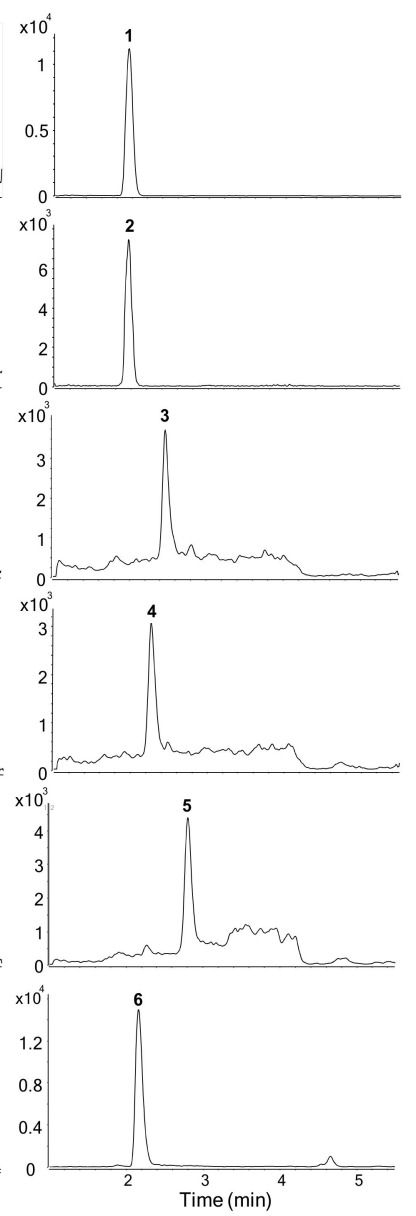

Figure 3. Selected reaction monitoring chromatograms of (A) mouse blank plasma: (B) Mouse plasma spiked with doxorubicin $(0.5 \mathrm{ng} / \mathrm{mL})$, doxorubicinol $(0.1 \mathrm{ng} / \mathrm{mL})$, doxorubicinone $(0.01 \mathrm{ng} / \mathrm{mL})$, doxorubicinolone $(0.01 \mathrm{ng} / \mathrm{mL})$, and 7-deoxydoxorubicinone $(0.01 \mathrm{ng} / \mathrm{mL})$ at the lower limit of quantification (LLOQ) levels and daunorubicin as the internal standard at $100 \mathrm{ng} / \mathrm{mL}$; and (C) mouse plasma obtained $15 \mathrm{~min}$ after intravenous injection of doxorubicin at a dose of $1.3 \mathrm{mg} / \mathrm{kg}$ to a female BALB/c nude mouse. 1, Doxorubicin; 2, doxorubicinol; 3, doxorubicinone; 4, doxorubicinolone; 5 , 7-deoxydoxorubicinone; 6 , daunorubicin (internal standard).

\subsection{Method Validation}

Calibration curves were linear over the concentration ranges of $0.5-200 \mathrm{ng} / \mathrm{mL}$ for doxorubicin; 0.1-200 ng/mL for doxorubicinol; and 0.01-50 ng/mL for doxorubicinone, doxorubicinolone, and 7 -deoxydoxorubicinone in mouse plasma. The coefficients of determination were $\geq 0.9933$ from linear regression analysis with a weighting of $1 /$ concentration $^{2}$ (Table 1 ). The relative standard deviation (RSD) and relative error (RE) of the calculated concentrations were less than $15 \%$ and $\pm 15 \%$, respectively, for eight calibration points. The RSD values for the regression line slopes for the five analytes were $\leq 9.8 \%$, indicating good method repeatability. 
Table 1. Linearity, limit of detection (LOD), LLOQ, intra and inter-day accuracies (relative error (RE), $\%$ ), and precision (relative standard deviation (RSD), \%) of doxorubicin, doxorubicinol, doxorubicinone, doxorubicinolone, and 7-deoxydoxorubicinone in mouse plasma QC samples.

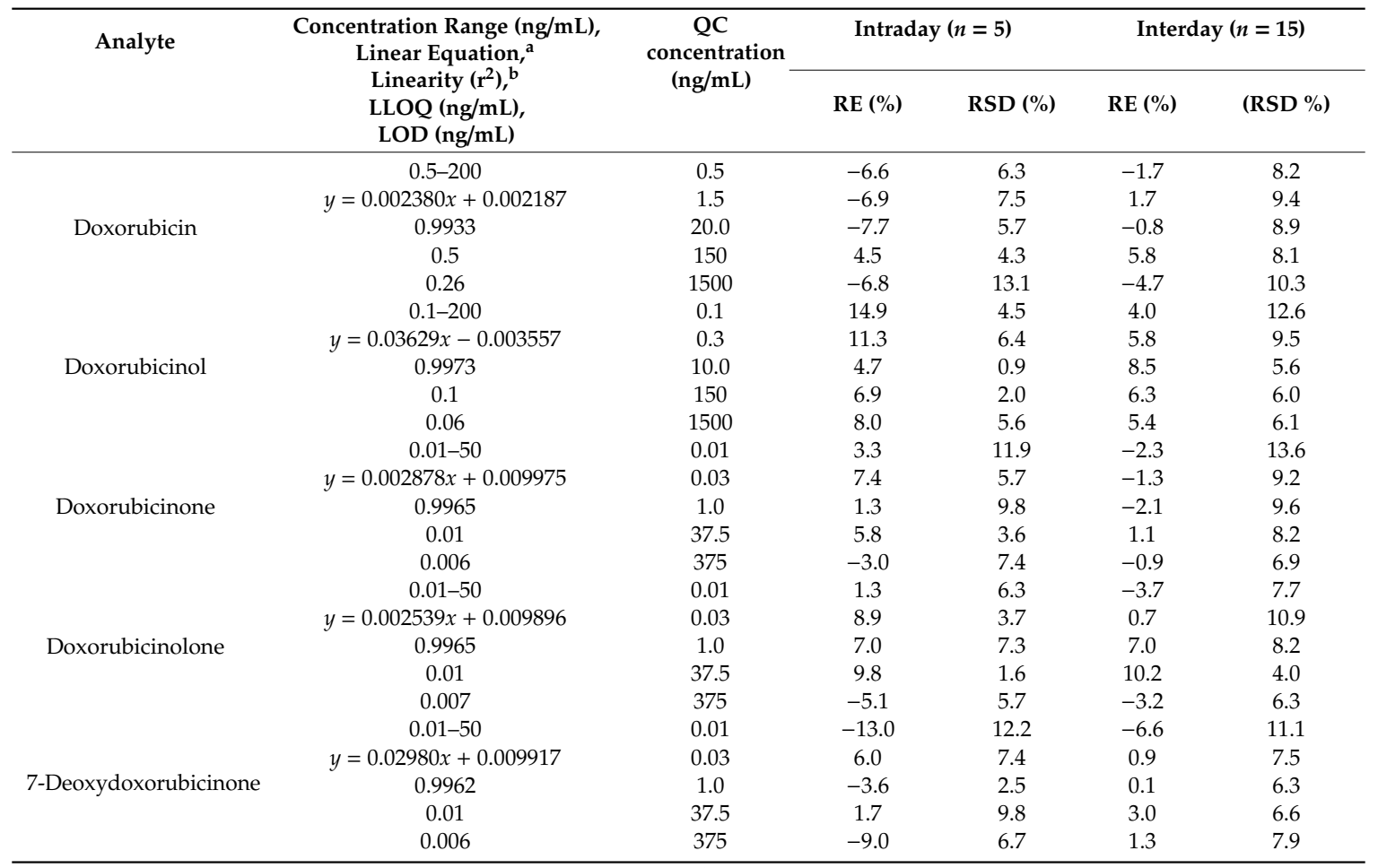

${ }^{\mathrm{a}} y$ : Peak area ratio, $x$ : concentration; ${ }^{\mathrm{b}} r^{2}$ : coefficients of determination.

The intra and inter-day RSD and RE values for the five analytes in low, medium, and high quality control (QC) samples ranged from $0.9 \%$ to $10.9 \%$ and from $-7.7 \%$ to $11.3 \%$, respectively (Table 1 ), indicating that the accuracy and precision of this method are acceptable. The intra and inter-day RSD and RE values for diluted QC plasma samples of the five analytes with dilution factor of 50 ranged from $5.6 \%$ to $13.0 \%$ and from $-9.0 \%$ to $8.0 \%$, respectively (Table 1 ), supporting good dilution integrity.

The LLOQ values for doxorubicin, doxorubicinol, doxorubicinone, doxorubicinolone, and 7-deoxydoxorubicinone were $0.5,0.1,0.01,0.01$, and $0.01 \mathrm{ng} / \mathrm{mL}$, respectively, in mouse plasma (Table 1). The RE and RSD values of the five analytes at the LLOQ QC levels were within the criteria of $\operatorname{RE}( \pm 20 \%)$ and RSD (20\%); i.e., $-13.0 \%$ to $14.9 \%$ and $4.5 \%$ to $13.6 \%$, respectively (Table 1 ). The limit of detection (LOD) values for doxorubicin, doxorubicinol, doxorubicinone, doxorubicinolone, and 7-deoxydoxorubicinone were $0.26,0.06,0.006,0.007$, and $0.006 \mathrm{ng} / \mathrm{mL}$, respectively (Table 1 ).

Using liquid-liquid extraction with chloroform:methanol $(4: 1, v / v)$, the recoveries of doxorubicin, doxorubicinol, doxorubicinone, doxorubicinolone, 7-deoxydoxorubicinone, and daunorubicin (IS) in mouse plasma were 81.7-86.4, 84.1-87.9, 77.0-90.4, 81.6-94.7, 81.3-87.7, and 108.8\%, respectively (Table 2). The matrix effects for doxorubicin, doxorubicinol, doxorubicinone, doxorubicinolone, 7-deoxydoxorubicinone, and daunorubicin (IS) were 112.9-119.7\%, 94.8-109.6\%, 105.1-117.9\%, 99.0-111.0\%, 98.3-108.3\%, and 88.0\%, respectively, with RSD $\leq 14.2 \%$ at low, medium, and high QC levels (Table 2), indicating the presence of a small matrix effect. Liquid-liquid extraction using chloroform:methanol $(4: 1, v / v)$ resulted in higher sensitivity and smaller matrix effects for doxorubicin and its four metabolites compared with the protein precipitation method using methanol, acetonitrile, or acetone [13-15,18,19,21,22,25-27,31,32,34,35]. Our method yielded LLOQ levels of doxorubicin $(0.5 \mathrm{ng} / \mathrm{mL})$ and its major four metabolites $(0.1-0.01 \mathrm{ng} / \mathrm{mL})$ that were better than those reported [11-36] using the least plasma volume of $10 \mu \mathrm{L}$. 
Table 2. Matrix effects and recoveries of doxorubicin, doxorubicinol, doxorubicinone, doxorubicinolone, 7-deoxydoxorubicinone, and daunorubicin (internal standard) using six different mouse plasma samples $(n=6)$.

\begin{tabular}{ccccc}
\hline \multirow{2}{*}{ Compound } & $\begin{array}{c}\text { Nominal } \\
\text { Concentration } \\
(\mathbf{n g} / \mathbf{m L})\end{array}$ & Mean & RSD (\%) & \multirow{2}{*}{$\begin{array}{c}\text { Recovery }^{\mathbf{b}} \\
\text { (mean } \pm \text { SD, \%) }\end{array}$} \\
\cline { 3 - 4 } & 1.5 & 112.9 & 3.6 & $85.3 \pm 8.6$ \\
Doxorubicin & 20 & 119.7 & 11.1 & $86.4 \pm 10.6$ \\
& 150 & 114.5 & 6.2 & $81.7 \pm 7.0$ \\
Doxorubicinol & 0.3 & 94.8 & 1.6 & $84.1 \pm 4.8$ \\
& 7.5 & 109.6 & 9.4 & $85.4 \pm 9.5$ \\
Doxorubicinone & 150 & 108.3 & 7.2 & $87.9 \pm 7.5$ \\
& 0.03 & 117.9 & 14.2 & $77.0 \pm 4.9$ \\
Doxorubicinolone & 1 & 108.1 & 7.8 & $90.4 \pm 6.8$ \\
& 37.5 & 105.1 & 5.2 & $86.5 \pm 8.6$ \\
7-Deoxydoxorubicinone & 1 & 111.0 & 12.1 & $81.6 \pm 6.1$ \\
& 1.03 & 99.0 & 7.0 & $94.7 \pm 3.9$ \\
Daunorubicin & 1 & 105.8 & 3.6 & $89.1 \pm 6.4$ \\
\hline
\end{tabular}

${ }^{\text {a }}$ Matrix effect was calculated as (peak area of each analyte spiked post-extraction of each blank plasma/mean peak area of the equivalent analyte standard solution) $\times 100 .{ }^{b}$ Recovery was calculated as (peak area of an analyte-spiked plasma prior to liquid-liquid extraction/peak area of an analyte spiked after liquid-liquid extraction of blank plasma) $\times 100$.

Table 3 presents three freeze-thaw, short-term storage on ice, and post-preparation stabilities of each analyte; these processes had negligible effects on sample stability.

Table 3. Post-preparation, short-term, and freeze-thaw stabilities of doxorubicin, doxorubicinol, doxorubicinone, doxorubicinolone, and 7-deoxydoxorubicinone in mouse plasma QC samples $(\mathrm{n}=3)$.

\begin{tabular}{|c|c|c|c|c|c|c|}
\hline \multirow{2}{*}{$\begin{array}{l}\text { Analytes and Nominal } \\
\text { Concentrations } \\
(\mathrm{ng} / \mathrm{mL})\end{array}$} & \multicolumn{2}{|c|}{$\begin{array}{l}\text { Post-Preparation } \\
\left(24 \mathrm{~h} \text { at } 4^{\circ} \mathrm{C}\right)\end{array}$} & \multicolumn{2}{|c|}{$\begin{array}{l}\text { Short-Term } \\
\text { ( } 2 \mathrm{~h} \text { on ice) }\end{array}$} & \multicolumn{2}{|c|}{$\begin{array}{c}\text { Freeze-Thaw } \\
\text { (Three Cycles of }-80{ }^{\circ} \mathrm{C} \\
\text { to Room Temperature) }\end{array}$} \\
\hline & $\mathrm{RE}, \%$ & RSD, \% & $\mathrm{RE}, \%$ & RSD, \% & $\mathrm{RE}, \%$ & RSD, \% \\
\hline \multicolumn{7}{|l|}{ Doxorubicin } \\
\hline 1.5 & 4.7 & 5.1 & 0.0 & 10.9 & -2.7 & 11.5 \\
\hline 150 & 7.6 & 6.4 & -4.9 & 10.4 & 4.3 & 2.6 \\
\hline \multicolumn{7}{|l|}{ Doxorubicinol } \\
\hline 0.3 & -6.9 & 12.0 & 13.6 & 6.9 & 0.1 & 10.6 \\
\hline 150 & 6.9 & 3.8 & -9.3 & 1.1 & 3.8 & 7.4 \\
\hline \multicolumn{7}{|l|}{ Doxorubicinone } \\
\hline 0.03 & -8.0 & 7.5 & 5.0 & 2.9 & -9.7 & 4.6 \\
\hline 37.5 & 3.3 & 5.6 & 0.2 & 10.2 & 5.9 & 2.7 \\
\hline \multicolumn{7}{|l|}{ Doxorubicinolone } \\
\hline 0.03 & -4.3 & 9.6 & 10.5 & 4.2 & 2.9 & 6.2 \\
\hline 37.5 & 12.2 & 6.5 & 3.4 & 5.9 & 5.7 & 1.9 \\
\hline \multicolumn{7}{|l|}{ 7-Deoxydoxorubicinone } \\
\hline 0.03 & 1.3 & 5.7 & -5.2 & 13.9 & -5.0 & 3.7 \\
\hline 37.5 & 12.2 & 5.4 & -0.8 & 9.8 & 1.7 & 2.8 \\
\hline
\end{tabular}

Incurred sample reanalysis (ISR) was performed by reanalyzing 10 mouse plasma samples obtained from the pharmacokinetic study in mice. The percentage differences between ISR and the original concentration values for all of the repeat samples were within $\pm 20 \%$, indicating ISR is successful and this method is reproducible. 


\subsection{Pharmacokinetics of Doxorubicin in Mice}

Figure 4 presents the mean plasma concentration-time profiles of doxorubicin and its four metabolites following an intravenous injection of doxorubicin at a dose of $1.3 \mathrm{mg} / \mathrm{kg}$ to female BALB/c nude mice. The mean plasma concentration-time profiles of doxorubicinol, doxorubicinone, doxorubicinolone, and 7-deoxydoxorubicinone, the major metabolites of doxorubicin (Figure 1) [6-10], were determined and compared to that of unchanged doxorubicin in plasma, after intravenous injection of doxorubicin to mice (Figure 4 , Table 4 ). The maximum plasma concentrations $\left(C_{\max }\right)$ of doxorubicinol, doxorubicinone, doxorubicinolone, and 7-deoxydoxorubicinone were 34.7 $\pm 9.3,1.2 \pm$ $0.3,1.3 \pm 0.3$, and $2.2 \pm 0.6 \mathrm{ng} / \mathrm{mL}$, respectively, at the first sampling point $(2 \mathrm{~min})$, supporting the rapid metabolism of doxorubicin. However, the plasma concentrations of doxorubicinone, doxorubicinolone, and 7-deoxydoxorubicinone were below the LLOQ $(0.01 \mathrm{ng} / \mathrm{mL})$ from $0.5 \mathrm{~h}$ after injection of doxorubicin (Figure 4), and therefore, other pharmacokinetic parameters of doxorubicinone, doxorubicinolone, and 7-deoxydoxorubicinone could not be calculated. Table 4 lists the pharmacokinetic parameters of doxorubicin and a major and active metabolite, doxorubicinol. The half-life of the primary metabolite doxorubicinol $(5.4 \mathrm{~h})$ was shorter than that of doxorubicin $(15.3 \mathrm{~h})$, and the area under the concentration-time curve to last time $\left(\mathrm{AUC}_{\text {last }}\right)$ of doxorubicinol was $0.38 \%$ of that of doxorubicin.

(A)

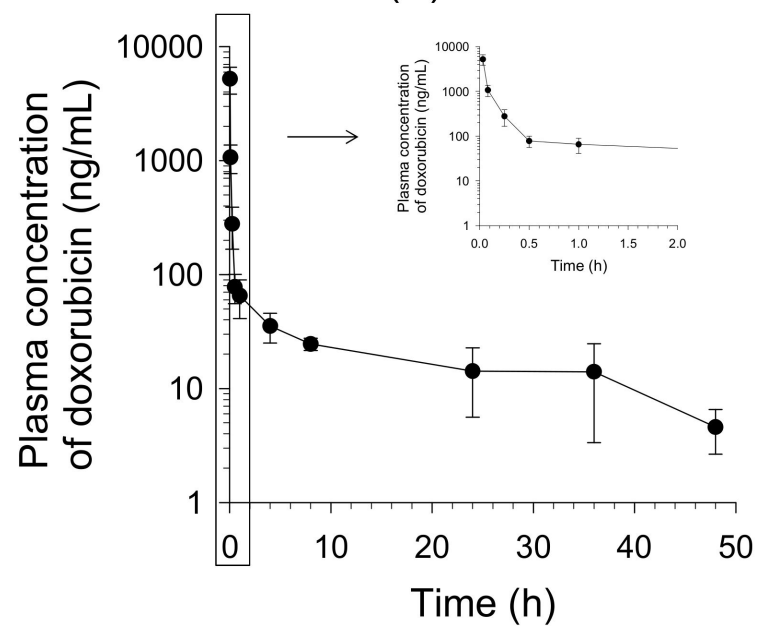

(B)

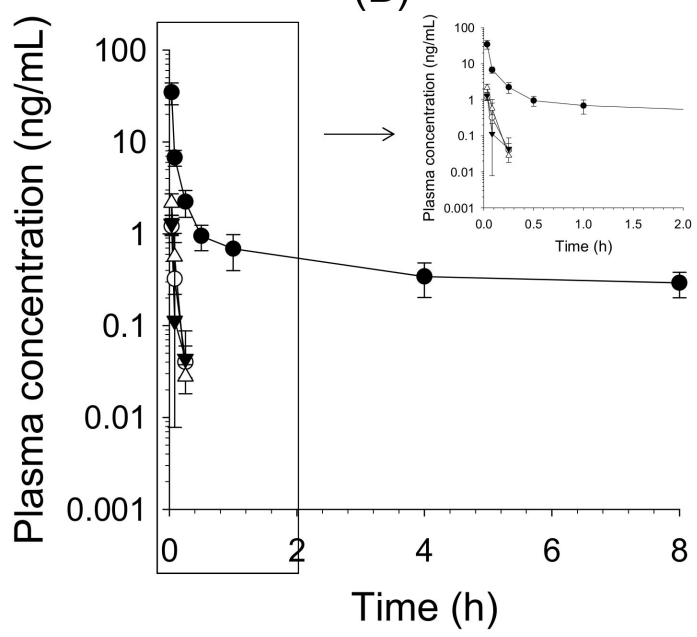

Figure 4. Mean plasma concentration-time profiles of (A) doxorubicin and (B) the four metabolites doxorubicinol $(\mathbf{})$, doxorubicinone $(\bigcirc)$, doxorubicinolone $(\boldsymbol{\nabla})$, and 7-deoxydoxorubicinone $(\triangle)$ after a single intravenous injection of doxorubicin at a dose of $1.3 \mathrm{mg} / \mathrm{kg}$ to female BALB/c nude mice. Points represent means \pm SDs $(n=5)$. The inset figures represent the plasma concentration-time curves of five analytes from $0 \mathrm{~h}$ to $2 \mathrm{~h}$. 
Table 4. Pharmacokinetic parameters of doxorubicin and its metabolite doxorubicinol after a single intravenous injection of doxorubicin at a dose of $1.3 \mathrm{mg} / \mathrm{kg}$ to female BALB/c nude mice. Data are shown as means \pm SDs $(n=5)$.

\begin{tabular}{|c|c|c|}
\hline Pharmacokinetic Parameters & Doxorubicin & Doxorubicinol \\
\hline Area under the & & \\
\hline $\begin{array}{l}\text { concentration-time curve to last } \\
\text { time }\left(\mathrm{AUC}_{\text {last }}, \mathrm{ng} \cdot \mathrm{h} / \mathrm{mL}\right)\end{array}$ & $1415.6 \pm 303.6$ & $5.4 \pm 1.1$ \\
\hline $\begin{array}{l}\text { AUC to infinite time }\left(\mathrm{AUC}_{\mathrm{inf}}\right. \\
\mathrm{ng} \cdot \mathrm{h} / \mathrm{mL})\end{array}$ & $1475.5 \pm 392.8$ & $7.6 \pm 2.4$ \\
\hline Clearance (CL, mL/h/kg) & $896 \pm 167$ & - \\
\hline $\begin{array}{c}\text { Volume of distribution at steady } \\
\text { state (Vss, } \mathrm{mL} / \mathrm{kg})\end{array}$ & $12,636 \pm 3410$ & - \\
\hline Half-life $\left(t_{1 / 2}, h\right)$ & $15.3 \pm 3.4$ & $5.4 \pm 3.2$ \\
\hline Mean residence time (MRT, h) & $9.4 \pm 1.8$ & - \\
\hline $\begin{array}{l}\text { Maximum plasma concentration } \\
\qquad\left(\mathrm{C}_{\max }, \mathrm{ng} / \mathrm{mL}\right)\end{array}$ & - & $34.7 \pm 9.3$ \\
\hline Time to reach $\mathrm{C}_{\max }\left(\mathrm{T}_{\max }, \mathrm{h}\right)$ & - & 0.033 \\
\hline
\end{tabular}

\section{Materials and Methods}

\subsection{Materials}

Doxorubicin (purity, 95.0\%) was obtained from MedKoo Biosciences (Morrisville, NC, USA). Doxorubicinol (purity, 90.0\%), doxorubicinone (purity, 98.0\%), doxorubicinolone (purity, 90.0\%), 7-deoxydoxorubicinone (purity, 95.0\%), and daunorubicin hydrochloride (purity, 96\%) were obtained from Toronto Research Chemicals Inc. (Toronto, ON, Canada). Dimethyl sulfoxide, chloroform, and formic acid were purchased from Sigma-Aldrich Co. (St. Louis, MO, USA). Water, acetonitrile, and methanol (LC-MS grade) were supplied by Fisher Scientific Co. (Fair Lawn, NJ, USA). All other chemicals used were of the highest quality available.

\subsection{Preparation of Calibration Standards and Quality Control Samples}

Each standard stock solution was prepared separately by dissolving doxorubicin, doxorubicinol, doxorubicinone, doxorubicinolone, and 7-deoxydoxorubicinone (1 mg each) in $1 \mathrm{~mL}$ of dimethyl sulfoxide. Mixed working standard solutions of the five analytes were prepared by mixing each working standard stock solution with methanol. IS working solution (daunorubicin hydrochloride, $100 \mathrm{ng} / \mathrm{mL}$ ) was prepared by diluting an aliquot of the stock solution with methanol. All standard solutions were stored at $4{ }^{\circ} \mathrm{C}$ in darkness for 4 weeks.

Mouse plasma calibration standards were prepared at eight concentration levels: 0.5, 1, 2, 5, 25, 100, 160, and $200 \mathrm{ng} / \mathrm{mL}$ for doxorubicin; 0.1, 0.2, 1, 5, 25, 100, 160, and $200 \mathrm{ng} / \mathrm{mL}$ for doxorubicinol; and $0.01,0.02,0.1,0.5,2.5,10,40$, and $50 \mathrm{ng} / \mathrm{mL}$ for doxorubicinone, doxorubicinolone, and 7-deoxydoxorubicinone. QC samples were prepared at the concentrations of 1.5, 20, and $150 \mathrm{ng} / \mathrm{mL}$ for doxorubicin; $0.3,10$, and $150 \mathrm{ng} / \mathrm{mL}$ for doxorubicinol; and 0.03, 1, and $37.5 \mathrm{ng} / \mathrm{mL} \mathrm{for}$ doxorubicinone, doxorubicinolone, and 7-deoxydoxorubicinone in drug-free mouse plasma and stored at $-80{ }^{\circ} \mathrm{C}$ until analyzed.

\subsection{Sample Preparation}

The $10 \mu \mathrm{L}$ aliquots of blank mouse plasma, calibration standards, and QC samples were stored on ice, and then vortex-mixed with $4 \mu \mathrm{L}$ of daunorubicin (IS) in methanol (100 ng/mL), $30 \mu \mathrm{L}$ of 50 $\mathrm{mM}$ potassium phosphate buffer ( $\mathrm{pH} 7.4)$, and $400 \mu \mathrm{L}$ of chloroform:methanol $(4: 1, v / v)$ for $10 \mathrm{~min}$. Following centrifugation at $10,000 \mathrm{~g}$ for $10 \mathrm{~min}, 300 \mu \mathrm{L}$ of the supernatant was transferred into a new amber polypropylene tube. The organic layer was evaporated to dryness at $35^{\circ} \mathrm{C}$ over $10 \mathrm{~min}$ using a vacuum evaporator (EZ-2 plus, Genevac Ltd., Ipswich, UK). The residues were dissolved in $30 \mu \mathrm{L}$ of 
$0.1 \%$ formic acid in $40 \%$ methanol and centrifuged. An aliquot $(3 \mu \mathrm{L})$ was injected onto the LC-MS/MS system for analysis.

\subsection{LC-MS/MS Analysis}

An ultra-performance liquid chromatograph (Agilent 1290; Agilent Technologies, Wilmington, DE, USA) coupled with a tandem mass spectrometer (Agilent 6495) was used for the LC-MS/MS analysis. Chromatographic separation was performed on a Luna Omega C18 column $(1.6 \mu \mathrm{m} ; 2.1$ $\mathrm{mm}$ i.d. $\times 50 \mathrm{~mm}$, Phenomenex, Torrance, CA, USA) using a gradient elution of $0.1 \%$ formic acid in $5 \%$ methanol (MP A) and 0.1\% formic acid in 95\% methanol (MP B) at a flow rate of $0.2 \mathrm{~mL} / \mathrm{min}$ as follows: $40 \% \mathrm{MP} \mathrm{B}$ for $0.25 \mathrm{~min}, 40 \%$ to $70 \% \mathrm{MP}$ B for $0.25 \mathrm{~min}, 70 \%$ to $85 \% \mathrm{MP} \mathrm{B}$ for $2 \mathrm{~min}, 85 \%$ to 98\% MP B for $0.1 \mathrm{~min}, 98 \% \mathrm{MP}$ B for $2.9 \mathrm{~min}, 98 \%$ to $40 \% \mathrm{MP}$ B for $0.1 \mathrm{~min}$, and $40 \% \mathrm{MP}$ B for $2.4 \mathrm{~min}$. The column and autosampler tray were maintained at $35^{\circ} \mathrm{C}$ and $4{ }^{\circ} \mathrm{C}$, respectively. The electrospray source settings for ionization of the analytes in positive mode were as follows: gas temperature, 260 ${ }^{\circ} \mathrm{C}$; gas flow, $11 \mathrm{~L} / \mathrm{min}$; nebulizer, $30 \mathrm{psi}$; sheath gas temperature, $400{ }^{\circ} \mathrm{C}$; sheath gas flow, $12 \mathrm{~L} / \mathrm{min}$; capillary voltage, $4000 \mathrm{~V}$; and nozzle voltage, $2000 \mathrm{~V}$. Nitrogen gas was used as the collision gas at a pressure of 2 bar on the instrument. The collision energies for the fragmentation of doxorubicin, doxorubicinol, doxorubicinone, doxorubicinolone, 7-deoxydoxorubicinone, and daunorubicin (IS) were $9,10,12,14,22$, and $30 \mathrm{eV}$, respectively. The SRM transitions for the quantification were as follows: $m / z 544.0 \rightarrow 397.0$ for doxorubicin; $m / z 546.1 \rightarrow 399.0$ for doxorubicinol; $m / z 437.0 \rightarrow 419.0$ for doxorubicinone; $m / z 438.9 \rightarrow 421.0$ for doxorubicinolone; $m / z$ 399.1 $\rightarrow 381.0$ for 7 -deoxydoxorubicinone; and $m / z 528.1 \rightarrow 321.0$ for daunorubicin. Mass Hunter software (Version B.07.00, Agilent Technologies, Wilmington, DE, USA) was used for LC-MS/MS system control and data processing.

\subsection{Method Validation}

Method validation was performed according to the methods set out in the FDA Guidance on Bioanalytical Method Validation. To evaluate intra and inter-day precisions and accuracies, we analyzed batches of calibration standards and QC samples in five replicates on three different days as follows: 1.5, 20, and $150 \mathrm{ng} / \mathrm{mL}$ for doxorubicin; 0.3, 10, and $150 \mathrm{ng} / \mathrm{mL}$ for doxorubicinol; and 0.03, 1, and $37.5 \mathrm{ng} / \mathrm{mL}$ for doxorubicinone, doxorubicinolone, and 7-deoxydoxorubicinone. Accuracy was defined as the RE (\%) of the measured mean value deviating from the nominal value, and precision was defined as the RSD (\%) of the measured concentration.

To evaluate the dilution integrity, mouse plasma samples spiked with $1500 \mathrm{ng} / \mathrm{mL}$ of doxorubicin and doxorubicinol; and $375 \mathrm{ng} / \mathrm{mL}$ of doxorubicinone, doxorubicinolone, and 7-deoxydoxorubicinone-which were diluted with pooled blank mouse plasma at dilution factors of 50 in five replicates and analyzed for three successive days.

The LLOQ value was defined as the lowest amount of each analyte in a mouse plasma sample that could be quantified as follows: signal-to-noise ratio $>5$; RSD $< \pm 20 \%$; RE $<20 \%$. Each LOD was calculated as $3 \delta / \mathrm{s}$, where $\delta$ is the standard deviation of the response near an expected LOD concentration $(n=7)$ and $\mathrm{s}$ is the slope of the calibration curve [40].

The stability of each of the five analytes in mouse plasma was evaluated by analyzing low and high QC samples in triplicate: post-preparation sample stability in the autosampler at $4{ }^{\circ} \mathrm{C}$ for $24 \mathrm{~h}$; short-term storage stability following storage of plasma samples on ice for $2 \mathrm{~h}$; and three freeze-thaw cycles.

The matrix effect for each analyte was assessed by comparing the peak areas of the analytes spiked after extraction into blank plasma extracts originating from six different mice to the mean peak areas for neat solutions of the analytes at three concentration levels. The recoveries of each analyte were determined by comparing the peak areas of the extract of analyte-spiked plasma with those of the analytes spiked post-extraction into six different blank plasma extracts at three concentration levels.

ISR was performed by reanalysis of 10 mouse plasma samples obtained from the pharmacokinetic study of doxorubicin in mice, where sample numbers were equivalent to $10 \%$ of the study sample 
size. The percentage difference of the results between the original analysis and the repeat analysis was determined with the following equation:

$$
\frac{(\text { repeat }- \text { original }) \times 100}{\text { mean }}
$$

\subsection{Pharmacokinetic Study of Doxorubicin in Mice}

This validated method was applied to the pharmacokinetic study of doxorubicin and its metabolites after a single intravenous injection of doxorubicin at a dose of $1.3 \mathrm{mg} / \mathrm{kg}$ to BALB/c nude female mice ( $n=5$; body weights, 16.4-18.2 g; Orient Bio, Seongnam, Korea). The study protocol was approved by the Institutional Animal Care and Use Committee at the Catholic University of Korea (approval number 2019-036-01). Animals were kept in plastic cages with unlimited access to standard a mouse diet (Orient Bio) and water before the experiment, and were maintained at a temperature of $23 \pm 2$ ${ }^{\circ} \mathrm{C}$, a $12 \mathrm{~h}$ light/dark cycle, and a relative humidity of $50 \% \pm 10 \%$. Doxorubicin hydrochloride was dissolved in normal saline and administered to the tail vein of the mice at a dose of $1.3 \mathrm{mg} / \mathrm{kg}$. A blood sample (approximately $40 \mu \mathrm{L}$ ) was collected from the retro-orbital plexus of an individual mouse under light anesthesia with isoflurane at 2, 5, 15, and $30 \mathrm{~min}$, and at 1, 4, 8, 24, 36, and $48 \mathrm{~h}$ after drug administration. Plasma samples were harvested by centrifugation at $10,000 \mathrm{~g}$ for $5 \mathrm{~min}$ at $4{ }^{\circ} \mathrm{C} ; 10 \mu \mathrm{L}$ plasma samples were immediately collected in $1.5-\mathrm{mL}$ amber polypropylene microcentrifuge tubes and stored at $-80^{\circ} \mathrm{C}$ until LC-MS/MS analysis.

Pharmacokinetic parameters, including the area under the plasma concentration-time curve during the period of observation $\left(A U C_{\text {last }}\right)$, $A U C$ to infinite time $\left(A U C_{i n f}\right)$, the terminal half-life $\left(t_{1 / 2}\right)$, clearance $(C L)$, volume of distribution at steady state $\left(V_{\mathrm{ss}}\right)$, and mean residence time (MRT), were evaluated using noncompartmental analysis (WinNonlin; Pharsight, Mountain View, CA, USA). The maximum plasma concentration $\left(C_{\max }\right)$ and the time to reach $C_{\max }\left(T_{\max }\right)$ of the metabolites were directly obtained from the experimental data. Each value is expressed as the mean \pm standard deviation (SD).

\section{Conclusions}

A sensitive and rapid LC-MS/MS method using liquid-liquid extraction as a sample clean-up procedure was for the first time developed and validated for the simultaneous determination of doxorubicin and its major four metabolites-doxorubicinol, doxorubicinone, doxorubicinolone, and 7-deoxydoxorubicinone-with LLOQ levels of $0.5,0.1,0.01,0.01$, and $0.01 \mathrm{ng} / \mathrm{mL}$, respectively, in $10 \mu \mathrm{L}$ of mouse plasma. This method was successfully applied to the pharmacokinetics study of doxorubicin and its four metabolites after intravenous administration of doxorubicin at $1.3 \mathrm{mg} / \mathrm{kg}$ dose to BALB/c female nude mice.

Author Contributions: conceptualization, H.S.L. and W.G.C.; data curation, W.-G.C., Y.S., and H.S.L.; formal analysis, K.D.K. and W.-G.C.; funding acquisition, H.S.L.; investigation, W.-G.C., K.D.K., Y.S., and R.P.; methodology, W.-G.C., K.D.K., Y.S., H.C.K., and H.S.L.; project administration, H.S.L.; resources, W.-G.C., D.K.K., and R.P.; supervision, H.S.L; validation, W.-G.C., K.D.K., Y.S., and R.P.; writing-original draft preparation, W.-G.C.; writing-review and editing, H.S.L., J.Y.L., H.C.K., and Y.-Y.C. All authors have read and agreed to the published version of the manuscript.

Funding: This work was supported by the National Research Foundation of Korea (NRF) grant funded by the Korea government (MSIT) (NRF-2017M3A9F5028608, NRF-2017R1A4A1015036, and NRF2020R1A4A2002894).

Conflicts of Interest: The authors declare no conflict of interest. 


\section{References}

1. Douedi, S.; Carson, M.P. Anthracycline medications (Doxorubicin). In StatPearls [Internet]; StatPearls Publishing: St. Petersburg, FL, USA, 2019.

2. Wenningmann, N.; Knapp, M.; Ande, A.; Vaidya, T.R.; Ait-Oudhia, S. Insights into doxorubicin-induced cardiotoxicity: Molecular mechanisms, preventive strategies, and early monitoring. Mol. Pharmacol. 2019, 96, 219-232. [CrossRef]

3. Cagel, M.; Grotz, E.; Bernabeu, E.; Moretton, M.A.; Chiappetta, D.A. Doxorubicin: nanotechnological overviews from bench to bedside. Drug Discov. Today 2017, 22, 270-281. [CrossRef] [PubMed]

4. Rivankar, S. An overview of doxorubicin formulations in cancer therapy. J. Cancer Res. Ther. 2014, 10, 853-858. [CrossRef] [PubMed]

5. Zidan, A.A.; El-Ashmawy, N.E.; Khedr, E.G.; Ebeid, E.M.; Salem, M.L.; Mosalam, E.M. Loading of doxorubicin and thymoquinone with F2 gel nanofibers improves the antitumor activity and ameliorates doxorubicin-associated nephrotoxicity. Life Sci. 2018, 207, 461-470. [CrossRef] [PubMed]

6. Takanashi, S.; Bachur, N.R. Adriamycin metabolism in man. Evidence from urinary metabolites. Drug Metab. Dispos. 1976, 4, 79-87.

7. Licata, S.; Saponiero, A.; Mordente, A.; Minotti, G. Doxorubicin metabolism and toxicity in human myocardium: role of cytoplasmic deglycosidation and carbonyl reduction. Chem. Res. Toxicol. 2000, 13, 414-420. [CrossRef] [PubMed]

8. Reis-Mendes, A.; Carvalho, F.; Remiao, F.; Sousa, E.; Bastos, M.L.; Costa, V.M. The main metabolites of fluorouracil + adriamycin + cyclophosphamide (FAC) are not major contributors to FAC toxicity in H9c2 cardiac differentiated cells. Biomolecules 2019, 9, 1-20. [CrossRef]

9. Schaupp, C.M.; White, C.C.; Merrill, G.F.; Kavanagh, T.J. Metabolism of doxorubicin to the cardiotoxic metabolite doxorubicinol is increased in a mouse model of chronic glutathione deficiency: A potential role for carbonyl reductase 3. Chem. Biol. Interact. 2015, 234, 154-161. [CrossRef]

10. Derek, W.E.; Rashmi, N.; Simon, C.; Kyle, M.B.; Jonathan, P.J.M.; Amadeo, M.P. Role of drug metabolism in the cytotoxicity and clinical efficacy of anthracyclines. Curr. Drug Metab. 2015, 16, 412-426.

11. Beijnen, J.H.; Meenhorst, P.L.; Gijn, R.V.; Fromme, M.; Rosing, H.; Underberg, W.J.M. HPLC determination of doxorubicin, doxorubicinol and four aglycone metabolites in plasma of AIDS patients. J. Pharm. Biomed. Anal. 1991, 9, 995-1002. [CrossRef]

12. Zhou, Q.; Chowbay, B. Determination of doxorubicin and its metabolites in rat serum and bile by LC: application to preclinical pharmacokinetic studies. J. Pharm. Biomed. Anal. 2002, 30, 1063-1074. [CrossRef]

13. Reddy, L.H.; Meda, N.; Murthy, R.R. Rapid and sensitive HPLC method for the estimation of doxorubicin in dog blood - The silver nitrate artifact. Acta Pharm. 2005, 55, 81-91.

14. Wei, G.; Xiao, S.; Si, D.; Liu, C. Improved HPLC method for doxorubicin quantification in rat plasma to study the pharmacokinetics of micelle-encapsulated and liposome-encapsulated doxorubicin formulations. Biomed Chromatogr. 2008, 22, 1252-1258. [CrossRef] [PubMed]

15. Al-Abd, A.M.; Kim, N.H.; Song, S.-C.; Lee, S.J.; Kuh, H.-J. A simple HPLC method for doxorubicin in plasma and tissues of nude mice. Arch. Pharm. Res. 2009, 32, 605-611. [CrossRef] [PubMed]

16. Alhareth, K.; Vauthier, C.; Gueutin, C.; Ponchel, G.; Moussa, F. HPLC quantification of doxorubicin in plasma and tissues of rats treated with doxorubicin loaded poly(alkylcyanoacrylate) nanoparticles. J. Chromatogr. B 2012, 887-888, 128-132. [CrossRef] [PubMed]

17. Daeihameda, M.; Haeri, A.; Dadashzadeh, S. A simple and sensitive HPLC method for fluorescence quantitation of doxorubicin in micro-volume plasma: Applications to pharmacokinetic studies in rats. Iranian J. Pharm. Res. 2015, 14, 33-42.

18. Niu, H.; Xu, M.; Li, S.; Chen, J.; Luo, J.; Zhao, X.; Gao, C.; Li, X. High-performance liquid chromatography (HPLC) quantification of liposome-delivered doxorubicin in arthritic joints of collagen-induced arthritis rats. Med. Sci. Monit. Basic Res. 2017, 23, 150-158.

19. Han, J.; Zhang, J.; Zhao, H.; Li, Y.; Chen, Z. Simultaneous determination of doxorubicin and its dipeptide prodrug in mice plasma by HPLC with fluorescence detection. J. Pharm. Anal. 2016, 6, 199-202. [CrossRef]

20. Sanson, A.L.; Silva, S.C.R.; Martins, M.C.G.; Giusti-Paiva, A.; Maia, P.P.; Martins, I. Liquid-liquid extraction combined with high performance liquid chromatography-diode array-ultra-violet for simultaneous determination of antineoplastic drugs in plasma. Brazilian J. Pharm. Sci. 2011, 47, 363-371. [CrossRef] 
21. Dharmalingam, S.R.; Ramamurthy, S.; Chidambaram, K.; Nadaraju, S. A simple HPLC bioanalytical method for the determination of doxorubicin hydrochloride in rat plasma: Application to pharmacokinetic studies. Tropical J. Pharm. Res. 2014, 13, 409-415. [CrossRef]

22. Cao, P.; Bae, Y. Comparison between microplate spectrometry and LC/MS chromatography for facile pilot pharmacokinetics and biodistribution studies of doxorubicin-loaded nanoparticle drug carriers. J. Appl. Pharm. Sci. 2012, 2, 1-9.

23. Lachâtrea, F.; Marqueta, P.; Ragota, S.; Gauliera, J.M.; Cardotb, P.; Dupuya, J.L. Simultaneous determination of four anthracyclines and three metabolites in human serum by liquid chromatography-electrospray mass spectrometry. J. Chromatogr. B 2000, 738, 281-291. [CrossRef]

24. Mazuel, C.; Grove, J.; Gerin, G.; Keenan, K.P. HPLC-MS/MS determination of a peptide conjugate prodrug of doxorubicin, and its active metabolites, leucine-doxorubicin and doxorubicin, in dog and rat plasma. J. Pharm. Biomed. Anal. 2003, 33, 1093-1102. [CrossRef]

25. Arnold, R.D.; Slack, J.E.; Straubinger, R.M. Quantification of doxorubicin and metabolites in rat plasma and small volume tissue samples by liquid chromatography/electrospray tandem mass spectroscopy. J. Chromatogr. B 2004, 808, 141-152. [CrossRef] [PubMed]

26. Park, J.S.; Kim, H.-K.; Lee, H.Y.; Lee, M.-H.; Kim, H.G.; Chae, S.W.; Chae, H.J. Validation of a HPLC MS/MS Method for Determination of Doxorubicin in Mouse Serum and its Small Tissues. Kor. J. Clin. Pharm. 2006, 16, 23-27.

27. Liu, Y.; Yang, Y.; Liu, X.; Jiang, T. Quantification of PEGylated liposomal doxorubicin and doxorubicinol in rat plasma by liquid chromatography/electrospray tandem mass spectroscopy: Application to preclinical pharmacokinetic studies. Talanta 2008, 74, 887-895. [CrossRef] [PubMed]

28. Xu, J.; Liu, Y.; Yu, Y.; Ni, Q.; Chen, Y. Subcellular quantification of doxorubicin and its metabolite in cultured human leukemia cells using liquid chromatography-tandem mass spectrometry. Anal. Lett. 2012, 45, 1980-1994. [CrossRef]

29. Huan, M.; Tian, S.; Cui, H.; Zhang, B.; Su, D.; Wang, J.; Li, K.; Cao, W. Deposition of doxorubicin in rats following administration of three newly synthesized doxorubicin conjugates. Biomed. Res. Int. 2013, 2013, 926584. [CrossRef]

30. Sottani, C.; Poggi, G.; Melchiorre, F.; Montagna, B.; Minoia, C. Simultaneous measurement of doxorubicin and reduced metabolite doxorubicinol by UHPLC-MS/MS in human plasma of HCC patients treated with TACE. J. Chromatogr. B 2013, 915-916, 71-78. [CrossRef]

31. Ma, W.; Wang, J.; Guo, Q.; Tu, P. Simultaneous determination of doxorubicin and curcumin in rat plasma by LC-MS/MS and its application to pharmacokinetic study. J. Pharm. Biomed. Anal. 2015, 111, $215-221$. [CrossRef]

32. Sambasivam, G.; Shewade, D.G.; Dubashi, B.; Sundaram, R. A simple and rapid method for simultaneous quantification of doxorubicin, epirubicin, cyclophosphamide and 5-fluorouracil in human plasma by LCMS/MS. World J. Pharm. Res. 2016, 5, 747-757. [CrossRef]

33. Mazzucchelli, S.; Ravelli, A.; Gigli, F.; Minoli, M.; Corsi, F.; Ciuffreda, P.; Ottria, R. LC-MS/MS method development for quantification of doxorubicin and its metabolite 13-hydroxy doxorubicin in mice biological matrices: Application to a pharmaco-delivery study. Biomed. Chromatogr. 2017, 31, e3863. [CrossRef] [PubMed]

34. Wang, J.; Li, Y.; Ma, W.; Wang, X.; Tu, P. Validated LC-MS/MS method for simultaneous determination of doxorubicin and curcumin in polymeric micelles in subcellular compartments of MCF-7/Adr cells by protein precipitation-ultrasonic breaking method. Biomed. Chromatogr. 2017, 31, e3892. [CrossRef] [PubMed]

35. He, W.; Martin, J.H.; Shaw, P.N.; Lu, X.; Walpole, E.T.; Dimeski, G. A Simple and Sensitive LC-MS/MS Method for the Simultaneous Determination of Cyclophosphamide and Doxorubicin Concentrations in Human Plasma. Curr. Pharm. Anal. 2017, 14, 53-59. [CrossRef]

36. Xie, Y.; Shao, N.; Jin, Y.; Zhang, L.; Jiang, H.; Xiong, N.; Su, F.; Xu, H. Determination of non-liposomal and liposomal doxorubicin in plasma by LC-MS/MS coupled with an effective solid phase extraction: In comparison with ultrafiltration technique and application to a pharmacokinetic study. J. Chromatogr. B 2018, 1072, 149-160. [CrossRef]

37. Anderson, A.B.; Ciriacks, C.M.; Fuller, K.M.; Arriaga, E.A. Distribution of zeptomole-abundant doxorubicin metabolites in subcellular fractions by capillary electrophoresis with laser-induced fluorescence detection. Anal. Chem. 2003, 75, 8-15. [CrossRef] 
38. Eder, A.R.; Chen, J.S.; Arriaga, E.A. Separation of doxorubicin and doxorubicinol by cyclodextrin-modified micellar electrokinetic capillary chromatography. Electrophoresis 2006, 27, 3263-3270. [CrossRef]

39. Wang, Y.; Hong, J.; Cressman, E.N.; Arriaga, E.A. Direct sampling from human liver tissue cross sections for electrophoretic analysis of doxorubicin. Anal. Chem. 2009, 81, 3321-3328. [CrossRef]

40. Harris, D.C. Exploring chemical analysis (5th ed.). W.H. Freeman and Company: New York, NY, USA, 2013.

Sample Availability: Samples of the compounds are not available from the authors.

(C) 2020 by the authors. Licensee MDPI, Basel, Switzerland. This article is an open access article distributed under the terms and conditions of the Creative Commons Attribution (CC BY) license (http://creativecommons.org/licenses/by/4.0/). 